\title{
Predictors of incidence and prevalence of green tobacco sickness among Latino farmworkers in North Carolina, USA
}

\author{
T A Arcury, S A Quandt, J S Preisser
}

\begin{abstract}
Study objective-The characteristics of some populations make epidemiological measurement extremely difficult. The objective of this study is to identify risk factors that explain variation among incidence densities and proportions of one occupational illness, green tobacco sickness, within one such special population, Latino migrant and seasonal farmworkers in the United States.
\end{abstract}

Design-Prospective cohort study. Setting-37 farmworker residential sites located in Granville and Wake Counties, North Carolina, USA.

Participants-182 migrant and seasonal farmworkers that included 178 Latino men, three Latino women, and one nonHispanic white man.

Main results-Green tobacco sickness had a prevalence of 0.082 , and an incidence density of events per 100 days of 1.88 among the farmworkers. Prevalence and incidence density increased from early to late agricultural season. Major risk factors included lack of work experience, work activities, and working in wet clothes. Tobacco use was protective.

Conclusion-Green tobacco sickness has a high incidence among migrant and seasonal farmworkers. Because workers have little control over most risk factors, further research is needed to identify ways to prevent this occupational illness.

Department of Family and Community Medicine, Wake Forest University School of Medicine, Winston-Salem NC 27157-1084, USA

T A Arcury

Section on Epidemiology, Department of Public

Health Sciences, Wake Forest University

School of Medicine S A Quandt

Department of Biostatistics, University of North Carolina at Chapel Hill

J S Preisser

Correspondence: Dr Arcury (tarcury@wfubmc.edu)

Accepted for publication 22 May 2001 of fitting multivariate models of green tobacco sickness risk factors.

Green tobacco sickness is acute nicotine poisoning caused by the dermal absorption of nicotine from mature tobacco plants, Nicotiana tabacum. ${ }^{1}$ There are no established diagnostic criteria for green tobacco sickness. Symptoms include dizziness or headache and nausea or vomiting, but may also include abdominal cramps, headache, prostration, difficulty breathing, abdominal pain, diarrhoea, and occasionally fluctuations in blood pressure or heart rate. ${ }^{1-12}$ Green tobacco sickness is normally a self limiting condition from which workers recover in two or three days. However, symptoms are often severe enough to result in dehydration and the need for emergency medical care.

The first medical report of green tobacco sickness was published in 1970 based on cases in Florida ${ }^{13}$ Reports of green tobacco sickness have since been published describing its occurrence in North Carolina among white farm$\mathrm{ers}^{214}$ and Latino farmworkers, ${ }^{15}$ as well as in Kentucky, ${ }^{11}{ }^{12} 16$ India, ${ }^{7-10}$ and Japan. ${ }^{17}$ Data on green tobacco sickness incidence or prevalence are limited. Gehlbach et $a l^{14}$ reported the earliest estimate of green tobacco sickness prevalence, stating that, "during the 1973 harvesting season, an estimated $9 \%$ of North Carolina's 60000 tobacco growers reported illness among their workers"(page 478). $\mathrm{CDC}^{3}$ reported that the crude two month incidence rate for hospital treated green tobacco sickness in Kentucky during 1992 was 10 per 1000 workers. Quandt et $a l^{15}$ found $41 \%$ of 144 Latino migrant and seasonal farmworkers interviewed at the end of the 1998 season in North Carolina reported having green tobacco sickness at least once during that season. There are no data on green tobacco sickness among African American farmers or farmworkers.

Quandt and colleagues ${ }^{15}$ present a biobehavioural model of green tobacco sickness (fig 1) based on the existing green tobacco sickness research and on the physiology of percutaneous absorption of nicotine and other chemicals. ${ }^{18-21}$ They argue that green tobacco sickness results from the rate of transdermal absorption of nicotine, determined by the amount of dermal exposure to tobacco plants as well as several other factors. Dermal exposure to nicotine is increased by greater skin exposure and work activities that increase contact with the plants. Wearing protective clothing (for example, a plastic rain suit) decreases exposure, as does 


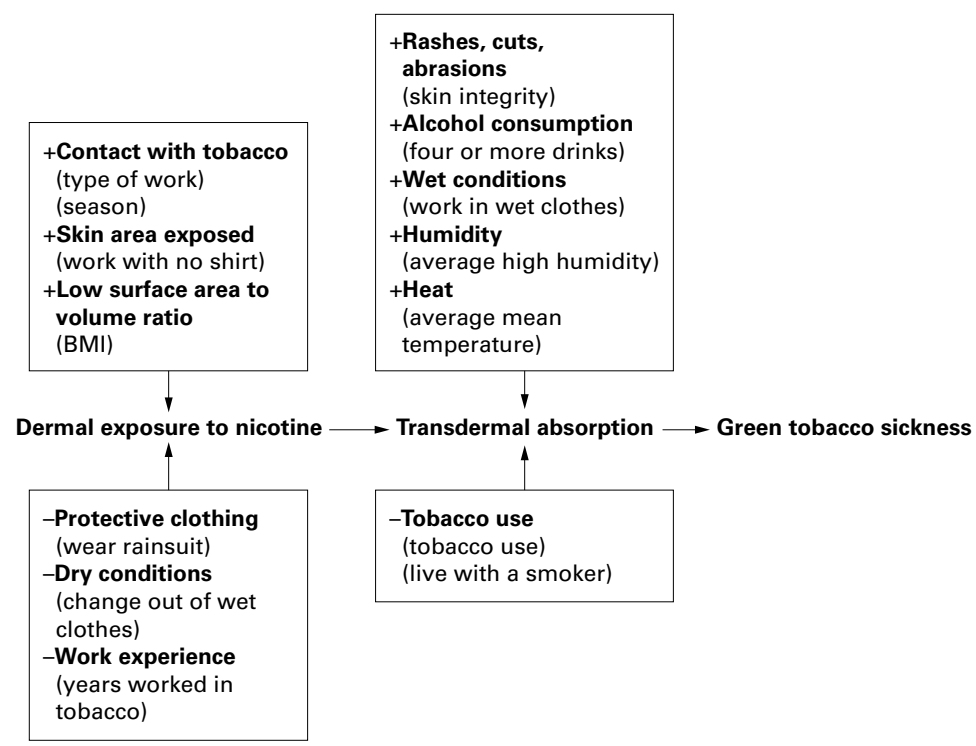

Figure 1 Biobehavioural model of green tobacco sickness causation (based on Quandt et $\left.a l^{15}\right)$.

learned avoidance gained through work experience with tobacco. ${ }^{10}$ The relation of dermal exposure to transdermal absorption is mediated by several factors. Compromised skin integrity (for example, cuts, rashes) ${ }^{10}$ may increase absorption, as may factors that increase vasodilatation, particularly consumption of alcoholic beverages and work in hot and humid weather. Working in wet tobacco also increases dermal absorption because nicotine is water soluble. ${ }^{18}{ }^{22}$ Use of tobacco products (smoking or smokeless) seems to decrease absorption. $^{211} 14$

\section{Methods}

This study used a prospective cohort design to collect data from Latino migrant and seasonal farmworkers in North Carolina. Migrant and seasonal farmworkers in North Carolina are largely Latino. ${ }^{23}{ }^{24}$ The study followed up and interviewed a total of 182 workers from one to five times over the summer of 1999, giving a total of 701 interviews.

SAMPLE SELECTION

Sample selection began with the random selection of 36 farmworker residence sites evenly divided between those served by migrant clinics in Wake and Granville Counties, North Carolina. These counties were selected because they differ in the size of farms. Granville is the more northern of the two counties and is characterised by hilly terrain with small farms. Wake is closer to the coastal plain and has flatter terrain and relatively large farms.

Lists of residence sites were compiled by migrant clinics in each county from previous years' experience. The list for Granville County included 72 sites, while the list for the Wake County included 110 sites. Sixty five sites were visited in random order (according to a permutation of the original list generated with the use of $\mathrm{SAS}^{25}$ ) to attain the desired sample of 36 sites, as 29 of the sites were not in use (18 from Granville County, 11 from Wake County) and were randomly replaced. All selected sites were visited, a census taken, and preliminary consent obtained from residents. All residents at inhabited sites agreed to participate. The initial goal was to recruit five workers at each site. At 13 sites with fewer than five residents, all farmworkers were recruited. At 21 sites with at least five residents, between five and seven were recruited; at two of these sites four participants were recruited. As there were so many sites with fewer than five resident farmworkers, attempts were made to recruit more than five participants at some sites. At the end of the initial recruitment period the sample included 169 farmworkers from 36 sites. Between the initial period and the first follow up one entire site was abandoned by its residents, and a 37th site was selected for participation. There was sufficient turnover of workers at some sites that some replacement of workers who had left the area was needed. For the third to final follow up interview periods, new residents were randomly selected and recruited if more than three sampled residents from that site were reported by other residents to have permanently left the site. All replacement resulted in the addition of 18 farmworkers to the sample. If a sampled resident who had not permanently left the site could not be located for an interview within two days before and three days after the scheduled two week follow up, this interview was not completed.

The total sample included 187 farmworkers. However, after examination of the data we found that five of the farmworkers who worked on farms that produced tobacco had never actually worked in tobacco during the entire data collection period, and were therefore not at risk for green tobacco sickness. These workers were excluded from the final sample. The final sample included 701 data points from 182 farmworkers with one to five data points per farmworker. This sample included 178 Hispanic men, three Hispanic women, and one non-Hispanic white man.

\section{DATA COLLECTION}

Data were collected by three interviewers bilingual in English and Spanish. The interview questionnaire was developed in English to ensure all of the topics important to the data collection were included. The questionnaire and the consent form were translated into Spanish by a professional translator. These were then reviewed by native Spanish speakers from Mexico who had been farmworkers. The questionnaire and consent form were then pretested with eight farmworkers. At baseline (defined as a worker's first interview) questions addressed personal and background characteristics, such as age, country of origin, length of residence in the US, educational attainment, general health, and ability to speak English. At each interview workers were asked hours worked in tobacco and type of work, possible risk factors encountered, and green tobacco sickness symptoms for the seven day period including the interview day and the previous six days. Other questions obtained data for the previous week on tobacco and alcohol use, 
actions taken to prevent green tobacco sickness, and use of health services. Interviewers examined hands and forearms to record the number of cuts, scrapes and rashes. Respondents self reported rashes elsewhere on the upper body.

Interviewing began on 21 June 1999. All participants gave informed consent. As part of informed consent, workers were told they would be given a tee shirt as an incentive at baseline. At the second, third and fourth interviews, workers were told that they would be given health education materials (for example, brochures on HIV/AIDS risks). At the fifth and final interview, participants were told that they would be given a hat. Baseline interviews took about 20 minutes to complete. At approximately two week intervals the interviewers returned to each site and conducted the follow up interviews. Follow up interviews took approximately 15 minutes to complete. The final follow up interviews were completed by 5 September 1999. Interviews were normally conducted in the evening after working hours, or on weekends.

MEASUREMENT OF INDEPENDENT VARIABLES

The measures used in this analysis and their relation to the biobehavioural model of green tobacco sickness are included in figure 1 . The first factor that would increase dermal exposure to nicotine was the amount of contact with tobacco. Two variables are used to measure contact with mature tobacco plants. Type of work is based on dominant activity reported for a worker during the previous seven days. "Topping" refers to breaking the flower off the top of the plant. "Priming" refers to actually picking or harvesting the tobacco leaves. In the process of priming, workers move down rows of tobacco as fast as they can, reach into the plants and remove the ripe or prime leaves. Workers hold the leaves under their arms until they can hold no more or they reach the end of a row. They then place the leaves into a cart. "Barning" refers to putting the harvested tobacco into a barn for curing. "Other" refers to any other activity, such as driving a tractor or not working in tobacco. The agricultural season is divided into three seasons: early (21 June 21 to 18 July), middle (19 July to 8 August), and late (9 August to 5 September). The type and amount of agricultural work is seasonal. The factor "skin area exposed" was measured with the variable "work with no shirt", which has the value "yes" if worker reported working at least one day in the previous seven with no shirt on. A low surface area to volume ratio would also indicate high dermal exposure; this factor was measured with body mass index. Three factors would reduce the dermal exposure to tobacco. Wearing protective clothing is measured with the variable "wear rainsuit", which indicates whether a worker responded affirmatively concerning wearing a rainsuit during the preceding week to prevent getting sick while working in tobacco. The factor dry conditions is measured with the variable "change out of wet clothes", which indicates whether or not a worker reported having changed out of wet clothes during the preceding week. The factor work experience is measured with the variable "years worked in tobacco", which is grouped into the categories of first year, two to four years, five or more years.

Several factors may increase the transdermal absorption of nicotine. Rashes, cuts, abrasions are measured with the variable "skin integrity", which has the value "poor" if a worker had a scrape, a rash, or two or more cuts anywhere on the arms or upper torso; the value "good" was applied if a worker had no scrapes or rash, and no more than one cut. Alcohol consumption is measured with the variable "four or more drinks", which is defined as a participant indicating that he/she had consumed four or more alcoholic beverages on at least one day of the previous seven days. The factor wet conditions is measured with the variable "work in wet clothes", based on whether a worker had worked in wet clothes at least $25 \%$ of the hours worked during the previous seven days.

Humidity and heat are expected to increase transdermal absorption. Humidity and heat data were collected from daily reports provided by weather stations in each county. Raw data included "average relative humidity as a whole per cent" and "maximum temperature rounded to the nearest whole degree." Average mean humidity is the mean of the daily average relative humidity for the seven days of a data collection period. Average high temperature is calculated as the mean of the high temperatures reported for the seven days of the data collection period.

The factors that could reduce the transdermal absorption are related to tobacco use. Tobacco use is measured with the variable "tobacco use", which has the value "yes" if a participant reported smoking at least one cigarette or cigar or dipping snuff or chewing tobacco per day during the previous seven days. "Live with a smoker" has a value "yes" if a respondent reported that he or she shared a residence with one or more people who smoked tobacco.

OVERVIEW OF STATISTICAL METHODS

Statistical analysis focused on the estimation of the incidence density and prevalence of green tobacco sickness overall and for subgroups in the population defined by all tobacco workers in the region served by Wake County Human Services Migrant Clinics and Stovall Clinic (Granville County) in the 1999 tobacco growing season. Statistical methods for sample surveys were applied. These took a finite population sampling perspective using weights for workers based on the probability of selection into the sample and then adjusting these weights at each period for missed survey occasions including period-specific non-response because of drop out. In the construction of weights the 18 late recruits were regarded as being present in the population at the first interview time when the original sample was selected. The sampling weights account for the oversampling of sites in Granville county relative to sites in Wake county. 
Table 1 Sample characteristics

\begin{tabular}{lll}
\hline & \multicolumn{2}{l}{ Number of workers } \\
\cline { 2 - 3 } Variable & $n$ & $\%$ \\
\hline Age (y) & & \\
18 to 24 & 46 & 25.2 \\
25 to 34 & 78 & 48.9 \\
$\quad 35$ and older & 58 & 31.9 \\
Education & & \\
0 to 5 yrs & 58 & 32.0 \\
6 to 8 yrs & 64 & 36.4 \\
9 to 16 yrs & 59 & 32.6 \\
Understand English & & \\
$\quad$ some & 93 & 51.1 \\
$\quad$ none & 89 & 48.9 \\
Years worked in tobacco & & \\
first & 59 & 32.4 \\
2 to 4 & 75 & 41.2 \\
$\quad 5$ or more & 48 & 26.4 \\
Work contract & & \\
$\quad$ yes & 99 & 55.3 \\
no & 80 & 44.7 \\
\hline
\end{tabular}

The calculation of incidence densities and prevalences for subgroups of workers are described in the next section. Survey regression methods were applied to log linear Poisson models for incidence densities and to logistic regression models for prevalences to evaluate bivariable and multivariable relations. Sites where farmworkers lived were the primary sampling units. To these clusters we applied working independence correlation matrices, and adjusted standard errors for the survey design. Standard errors were determined using Taylor approximations and statistical significance was determined with large sample Wald $\chi^{2}$ tests. $^{26}{ }^{27}$ We used SUDAAN's PROC LOGISTIC procedure for fitting the logistic model to the clustered binary data of green tobacco sickness presence, ${ }^{28}$ and SAS PROC GENMOD with the SCWGT option specified

Table 2 Green tobacco sickness (GTS) incidence density $\times 100$ and prevalence

\begin{tabular}{lcccll}
\hline Dates (1999) & Week & $\begin{array}{l}\text { Number of } \\
\text { workers }\end{array}$ & $\begin{array}{l}\text { Number of } \\
\text { GTS events }\end{array}$ & $\begin{array}{l}\text { Incidence density } \\
\text { (standard error) }\end{array}$ & $\begin{array}{l}\text { Prevalence } \\
\text { (standard } \\
\text { error) }\end{array}$ \\
\hline $6 / 21-6 / 27$ & 1 & 54 & 2 & $0.94(0.96)$ & $0.037(0.036)$ \\
$6 / 28-7 / 05$ & 2 & 59 & 2 & $0.51(0.50)$ & $0.023(0.022)$ \\
$7 / 06-7 / 11$ & 3 & 49 & 2 & $0.65(0.44)$ & $0.037(0.025)$ \\
$7 / 12-7 / 18$ & 4 & 65 & 4 & $1.64(1.04)$ & $0.046(0.024)$ \\
$7 / 19-7 / 25$ & 5 & 73 & 5 & $0.83(0.47)$ & $0.044(0.025)$ \\
$7 / 26-8 / 02$ & 6 & 76 & 17 & $5.33(1.52)$ & $0.187(0.044)$ \\
$8 / 03-8 / 08$ & 7 & 59 & 3 & $0.69(0.49)$ & $0.039(0.028)$ \\
$8 / 09-8 / 16$ & 8 & 79 & 11 & $2.32(1.13)$ & $0.101(0.048)$ \\
$8 / 17-8 / 22$ & 9 & 54 & 5 & $0.95(0.75)$ & $0.057(0.045)$ \\
$8 / 23-8 / 29$ & 10 & 55 & 13 & $3.91(1.49)$ & $0.207(0.080)$ \\
$8 / 30-9 / 05$ & 11 & 37 & 1 & $1.36(1.12)$ & $0.077(0.065)$
\end{tabular}

One form dated 9/12 was counted as week 11 .

Table 3 Mean high temperature in degrees centigrade and relative humidity

\begin{tabular}{|c|c|c|c|c|c|}
\hline \multirow[b]{2}{*}{ Dates (1999) } & \multirow[b]{2}{*}{ Week } & \multicolumn{2}{|c|}{$\begin{array}{l}\text { Average high temperature } \\
\text { Mean (standard error) }\end{array}$} & \multicolumn{2}{|c|}{$\begin{array}{l}\text { Average mean humidity } \\
\text { Mean (standard error) }\end{array}$} \\
\hline & & Wake County & $\begin{array}{l}\text { Granville } \\
\text { County }\end{array}$ & Wake County & $\begin{array}{l}\text { Granville } \\
\text { County }\end{array}$ \\
\hline $6 / 21-6 / 27$ & 1 & $27.3(3.9)$ & $27.1(4.3)$ & $88.6(9.3)$ & $86.1(9.6)$ \\
\hline $6 / 28-7 / 05$ & 2 & $32.4(3.2)$ & $32.8(2.6)$ & $87.9(7.8)$ & $83.9(7.4)$ \\
\hline $7 / 06-7 / 11$ & 3 & $33.4(4.8)$ & $33.5(4.7)$ & $82.5(7.9)$ & $79.0(4.4)$ \\
\hline $7 / 12-7 / 18$ & 4 & $26.4(6.0)$ & $26.9(6.5)$ & $92.6(7.2)$ & $90.6(7.3)$ \\
\hline $7 / 19-7 / 25$ & 5 & $34.6(1.3)$ & $34.8(1.9)$ & $81.6(5.6)$ & $80.4(6.5)$ \\
\hline $7 / 26-8 / 02$ & 6 & $36.1(2.4)$ & $35.9(2.4)$ & $70.4(6.2)$ & $72.5(5.3)$ \\
\hline $8 / 03-8 / 08$ & 7 & $34.4(1.6)$ & $34.4(2.3)$ & $67.8(4.8)$ & $65.3(5.2)$ \\
\hline $8 / 09-8 / 16$ & 8 & $33.1(3.4)$ & $34.0(3.1)$ & $83.6(7.2)$ & $79.1(7.5)$ \\
\hline $8 / 17-8 / 22$ & 9 & $31.5(2.8)$ & $32.1(3.6)$ & $83.5(6.0)$ & $77.3(7.5)$ \\
\hline $8 / 23-8 / 29$ & 10 & $30.4(1.6)$ & $31.5(1.3)$ & $87.0(6.3)$ & $82.1(6.5)$ \\
\hline $8 / 30-9 / 05$ & 11 & $26.3(2.4)$ & $26.3(2.5)$ & $79.9(14.4)$ & $74.0(16.3)$ \\
\hline
\end{tabular}

One form dated $9 / 12$ was counted as week 11 . for sampling weights to fit the log linear models to the incidence densities accounting for time at risk. ${ }^{25}$ The log linear models specified the number of green tobacco sickness events as the outcome and the natural logarithm of time at risk as an offset to give interpretations for incidence densities. ${ }^{29}$

\section{CALCULATION OF INCIDENCE DENSITIES AND}

\section{PREVALENCES}

The calculation of incidence densities and prevalences was based upon the definition of a green tobacco sickness event: at each day within each seven day week, green tobacco sickness was defined as present if the farmworker was at risk, by working either that day or the previous day, and reported the constellation of symptoms that defined green tobacco sickness (for the first day of the seven day week, the worker was at risk if he worked the current day). In particular, the farmworker must have been at risk and reported vomiting or nausea and headaches or dizziness to be defined as having green tobacco sickness. If these conditions were met on two consecutive days, only one green tobacco sickness event was counted. The two days contributed just one day to the time at risk in the determination of the incidence density of green tobacco sickness. If the conditions were met on three or four consecutive days, two green tobacco sickness events were counted. The incidence density of green tobacco sickness, calculated overall or for any subgroup of workers was defined as the ratio of the weighted number of green tobacco sickness events divided by the weighted number of days at risk. Let $g_{i j k t}$ be the number of green tobacco sickness events for the $i$ th worker of the $j$ th site in the $k$ th region at period $t$, and let $d_{i j k t}$ be the corresponding number of days at risk. The incidence density of green tobacco sickness, with summation over all subjects defined to be in the subgroup of interest, was Incidence density $=\sum w_{i j k t} g_{i j k t} / \sum w_{i j k t} d_{i j k}$, where $w_{i j k t}$ was the inverse of the probability of selection into the sample adjusted for non-response and defined below. The expected number of green tobacco sickness events per 100 days at risk for a given subgroup was determined by multiplying incidence density by 100 .

For a survey week for a given worker, we also defined the dichotomous variable of whether at least one green tobacco sickness event occurred. The green tobacco sickness prevalence was defined as the percentage of workers with at least one green tobacco sickness event among those who worked at least one day in the week. As for the green tobacco sickness incidence, the green tobacco sickness prevalence was also calculated over all weeks combined for certain subgroups of workers, and for each week and for each season. Prevalence of green tobacco sickness is calculated as $\sum w_{i j k t} I\left(g_{i j k t} \geqslant 1\right) / \sum w_{i j k t} I\left(d_{i j k t} \geqslant 1\right)$ which gave the estimated fraction of worker weeks in which a worker had green tobacco sickness at least once out of all the weeks worked that define the subgroup. The notation $\mathrm{I}()$ represents the indicator function, so that $I(A)=1$ if A was true and $I(A)=0$ if $\mathrm{A}$ was false. 
Table 4 Green tobacco sickness (GTS) incidence densities (ID) $\times 100$ and prevalence by risk factors

\begin{tabular}{|c|c|c|c|c|}
\hline Variable & $\begin{array}{l}\text { Number of } \\
\text { interviews }\end{array}$ & GTS events & $\begin{array}{l}\text { Prevalence } \\
\text { (standard error) }\end{array}$ & $\begin{array}{l}\text { ID } \\
\text { (standard error) }\end{array}$ \\
\hline Overall & 660 & 65 & $0.082(0.018)$ & $1.88(0.45)$ \\
\hline \multicolumn{5}{|l|}{ Season ${ }^{\star} \dagger$} \\
\hline early (e) & 227 & 10 & $0.036(0.014)$ & $0.93(0.38)$ \\
\hline middle $(\mathrm{m})$ & 208 & 25 & $0.094(0.023)$ & $2.34(0.67)$ \\
\hline late (1) & 225 & 30 & $0.109(0.032)$ & $2.13(0.62)$ \\
\hline \multicolumn{5}{|l|}{ Type of work ${ }^{\star} \dagger$} \\
\hline prime & 93 & 21 & $0.203(0.056)$ & $4.04(1.24)$ \\
\hline prime/barn & 93 & 13 & $0.109(0.041)$ & $2.55(0.87)$ \\
\hline top & 274 & 24 & $0.073(0.021)$ & $1.86(0.60)$ \\
\hline barn & 99 & 5 & $0.035(0.028)$ & $0.62(0.49)$ \\
\hline other & 101 & 2 & $0.011(0.012)$ & $0.24(0.25)$ \\
\hline \multicolumn{5}{|c|}{ Work with no shirt } \\
\hline yes & 38 & 8 & $0.133(0.075)$ & $2.29(1.31)$ \\
\hline no & 622 & 57 & $0.078(0.018)$ & $1.85(0.47)$ \\
\hline \multicolumn{5}{|c|}{ Body mass index } \\
\hline$<25$ & 231 & 22 & $0.075(0.023)$ & $1.79(0.56)$ \\
\hline $25-29$ & 319 & 32 & $0.093(0.020)$ & $2.09(0.51)$ \\
\hline $30+$ & 110 & 11 & $0.068(0.029)$ & $1.49(0.71)$ \\
\hline \multicolumn{5}{|l|}{ Wear rainsuit } \\
\hline yes & 209 & 27 & $0.109(0.036)$ & $2.38(0.76)$ \\
\hline no & 450 & 38 & $0.068(0.014)$ & $1.60(0.41)$ \\
\hline \multicolumn{5}{|c|}{ Change out of wet clothes } \\
\hline yes & 312 & 40 & $0.116(0.024)$ & $2.27(0.50)$ \\
\hline no & 156 & 19 & $0.079(0.027)$ & $2.16(0.87)$ \\
\hline \multicolumn{5}{|c|}{ Years worked in tobacco ${ }^{\star}+$} \\
\hline first & 191 & 24 & $0.108(0.029)$ & $2.41(0.74)$ \\
\hline 2 to 4 & 272 & 29 & $0.096(0.018)$ & $2.30(0.51)$ \\
\hline 5 or more & 197 & 12 & $0.039(0.018)$ & $0.87(0.44)$ \\
\hline \multicolumn{5}{|l|}{ Skin integrity } \\
\hline good & 562 & 53 & $0.082(0.018)$ & $1.88(0.45)$ \\
\hline poor & 98 & 12 & $0.080(0.037)$ & $1.89(0.91)$ \\
\hline \multicolumn{5}{|c|}{ Four or more drinks } \\
\hline yes & 178 & 15 & $0.080(0.021)$ & $1.55(0.40)$ \\
\hline no & 480 & 50 & $0.083(0.021)$ & $2.04(0.54)$ \\
\hline \multicolumn{5}{|c|}{ Work in wet clothes ${ }^{\star}+$} \\
\hline$\geqslant 25 \%$ & 232 & 35 & $0.138(0.028)$ & $2.97(0.71)$ \\
\hline$<25 \%$ & 428 & 30 & $0.052(0.016)$ & $1.29(0.42)$ \\
\hline \multicolumn{5}{|l|}{ Tobacco use ${ }^{\star}+$} \\
\hline yes & 260 & 17 & $0.060(0.017)$ & $1.18(0.32)$ \\
\hline & 400 & 48 & $0.098(0.023)$ & $2.39(0.61)$ \\
\hline \multicolumn{5}{|c|}{ Live with a smoker } \\
\hline yes & 470 & 43 & $0.077(0.018)$ & $1.71(0.45)$ \\
\hline no & 189 & 21 & $0.087(0.027)$ & $2.16(0.70)$ \\
\hline
\end{tabular}

Tobacco use is yes if in the past seven days the worker smoked cigarettes or cigars, or dipped snuff. Work in wet clothes at least $25 \%$ of the days that were worked in a seven day period. ${ }^{\star}$ Prevalence $\mathrm{p}<0.05$. $†$ Incidence $\mathrm{p}<0.05$.
KEY POINTS

- Green tobacco sickness is acute nicotine poisoning experienced by tobacco workers.

- Farmworkers experienced green tobacco sickness two days for every 100 days at risk.

- Lack of work experience, picking late in the season, and working in wet clothing place workers at risk.

- Smoking protects workers from green tobacco sickness.

- Research is needed to identify ways workers can reduce their risk of green tobacco sickness.

density was 1.88 green tobacco sickness events in 100 days at risk (SE 0.45). Finally, the prevalence of green tobacco sickness was estimated to be 0.082 (SE 0.018). In other words, overall, workers had about an $8 \%$ chance of having green tobacco sickness during any given week.

Table 2 reports the incidence density and prevalence for each of the 11 weeks. Generally, the highest rates of green tobacco sickness occurred mid to late summer, and especially in weeks 6,8 and 10 . Table 3 reports weather statistics averaged over the days in a week and reported separately for the two regions in the study. Not adjusting for any other variables, temperature $(\mathrm{p}<0.05)$ was significantly related to green tobacco sickness incidence. However, humidity was not significantly related to green tobacco sickness. Neither average high temperature nor average mean daily humidity were found correlated with green tobacco sickness prevalence.

The incidence density of green tobacco sickness differed significantly by period, years worked in tobacco, type of work, tobacco use, and percentage of days worked in wet clothes (table 4). For example, the incidence density of green tobacco sickness was estimated to be 0.93 green tobacco sickness events out of every 100 days worked in the early season, increasing to 2.13 green tobacco sickness events out of every 100 days worked in the late season. Also, the incidence density of green tobacco sickness was estimated to be 4.04 green tobacco sickness events out of every 100 days worked when the primary task was priming, versus 1.86 when the primary task was topping.

Results based upon prevalence were similar with those based upon incidence. A worker had a $3.6 \%$ chance of having a green tobacco sickness event in any given week of work in the early season versus a $10.9 \%$ chance during a week of work in the late season. Similarly, a worker whose primary activity was priming had a $20.3 \%$ chance of having a green tobacco sickness event in any given week, versus a $7.3 \%$ chance if topping was the primary activity.

Table 5 reports results of multivariate models for incidence (Poisson regression) and prevalence (logistic regression). Both models identified fewer years experience, type of work, 
Table 5 Model adjusted estimates of incidence densities (ID) ratios and odds ratios from survey Poisson and logistic regression

\begin{tabular}{lcc}
\hline & $\begin{array}{l}\text { Poisson regression } \\
\text { ID ratio } \\
\text { (95\% confidence intervals) }\end{array}$ & $\begin{array}{l}\text { Logistic regression } \\
\text { Odds ratio } \\
\text { (95\% confidence intervals) }\end{array}$ \\
\hline Variable & $2.86(1.14,7.18)$ & $3.35(1.42,7.94)$ \\
$\begin{array}{l}\text { Experience (ref: 5 or more years) } \\
\quad \text { first year }\end{array}$ & $2.10(0.92,4.77)$ \\
$\quad$ 2-4 years & $10(0.80,5.48)$ & $17.31(2.12,140.8)$ \\
$\begin{array}{l}\text { Type of work (ref: other) } \\
\text { prime }\end{array}$ & $14.59(1.82,117)$ & $7.23(1.45,36.1)$ \\
prime/barn & $8.41(1.48,48.2)$ & $5.15(0.82,32.5)$ \\
$\quad$ top & $6.96(1.02,47.5)$ & $3.24(0.33,31.6)$ \\
$\quad$ barn & $2.72(0.30,24.8)$ & $0.49(0.33,0.74)$ \\
Tobacco user & $0.44(0.29,0.66)$ & $4.10(1.66,10.1)$ \\
Work in wet clothes & $2.27(0.77,6.67)$ &
\end{tabular}

Tobacco use is yes if in the past seven days the worker smoked cigarettes or cigars, or dipped snuff. Work in wet clothes is the percentage of hours worked in wet clothes.

and non-tobacco use as statistically significantly predictive of green tobacco sickness at the 0.05 level. All of these factors, in addition to per cent time working in wet clothes, were significant predictors of prevalence. The observed incidence density ratio for first year worked in tobacco versus five or more years was $2.41 / 0.87=2.77$ (table 4 ) and was similar to the multivariate adjusted estimate from the Poisson regression of 3.35 (table 5). Similarly, the corresponding observed odds ratio of getting green tobacco sickness (0.108/ $(1-0.108)) /(0.039 /(1-0.039))=2.98($ table 4$)$ is consistent with the adjusted odds ratio estimate of 2.86 (table 5). After adjusting for type of work, tobacco use, and percentage of days worked in wet clothes, workers in their first year of tobacco work experienced about three times the amount of green tobacco sickness as workers with five years or more. After adjusting for other variables, the difference in green tobacco sickness between those with two to four years experience and those with over five years of experience was not statistically significant. Additionally, table 5 reports the magnitude of multivariate adjusted statistically significant effects, including type of work, as well as the protective effect of tobacco on green tobacco sickness.

\section{Discussion}

It is apparent from these estimates that green tobacco sickness is a highly prevalent occupational illness. For every 100 days at risk, Latino migrant and seasonal farmworkers had green tobacco sickness for an estimated 1.88 days. The incidence density varied with task, so that while priming or harvesting tobacco, farmworkers had green tobacco sickness for four days of every 100 days at risk. An average of $8 \%$ of the farmworkers had green tobacco sickness in any given week. The prevalence varied temporally such that during the last third of the season, almost $11 \%$ of the farmworkers had green tobacco sickness each week.

Our main results were very similar to those obtained without using weights, which is equivalent to weighting all observations equally. The unweighted estimated overall incidence density of green tobacco sickness was 1.91 (SE 0.46) compared with the weighted estimate of 1.88 (SE 0.45). The unweighted estimated overall prevalence of green tobacco sickness was 0.098 (65 events of 660 interviews) compared with the weighted estimate of 0.082 (SE 0.018). Unweighted incidence density estimates in Wake and Granville counties were 1.75 and 2.07, respectively. Weights were used, in part, to account for this discrepancy and the different sampling fraction for selecting sites in each county. Finally, unweighted estimates of multivariate adjusted incidence density and odds ratios for experience and type of work were somewhat smaller than their weighted counterparts in table 5, but the overall significance of these two effects did not depend upon weights being used.

Our estimates of green tobacco sickness prevalence and incidence fall in the middle of earlier estimates. Few studies report any green tobacco sickness prevalence or incidence rates, and those that do are not based on designs that permit generalisation to any population. Gehlbach et $a l^{14}$ do not report their methods, and indicate only that $9 \%$ of farmers reported illness among their workers. The total number of workers with green tobacco sickness and the number at risk are not reported. Furthermore, some research indicates that green tobacco sickness cases may cluster so that those farms with any workers ill from green tobacco sickness may have had many workers sick from green tobacco sickness. ${ }^{30}$ CDC $^{3}$ reports a prevalence of only $1 \%$. However, their data were draw from hospital emergency rooms. Our experience in North Carolina is that it is only those with the most severe cases of green tobacco sickness who seek medical care. Quandt et $a l^{15}$ found that $41 \%$ of Latino farmworkers reported to have had green tobacco sickness some time during season, a prevalence rate almost twice as great as that we found. However, their information is based on retrospective data collected at the end of a work season.

Whatever the health implications of tobacco consumption, tobacco will continue to be grown around the world. The issue with which we must grapple is how to make it possible for those who must make a living producing tobacco to do so without having to suffer illness. Guided by a biobehavioural model of green tobacco sickness risk factors, this analysis has considered the effects of sets of factors that influence the incidence of green tobacco sickness. Several of the factors that influence dermal exposure to green tobacco significantly affect green tobacco sickness incidence. The type of work (priming), the period of the season, and working in wet clothes all increase green tobacco sickness incidence. Work experience decreases green tobacco sickness incidence. Two of the factors that regulate transdermal absorption also significantly affect green tobacco sickness incidence. Increasing temperature is positively associated with green tobacco sickness incidence, while tobacco use decreases green tobacco sickness incidence. However, temperature was not established as an independent predictor as it was not in the multivariate model.

Unfortunately, farmworkers have little control over several of the most important green tobacco sickness risk factors. They must work at picking tobacco when it needs to be picked, and they must work when the tobacco is wet 
and the temperature is high. Work experience must be gained over time, and cannot be immediately increased. Furthermore, the mechanism of how work experience reduces risk is not clear; it is possible that those who are most susceptible to green tobacco sickness simply stop doing this work. One of the more potent factors that reduces risk of green tobacco sickness is tobacco use. This behaviour is inadvisable because of the greater health risk associated with tobacco use. The only risk factor shown to have a significant association with green tobacco sickness over which farmworkers have some control is changing out of wet clothing. These results indicate that researchers need to explore a realistic way to prevent this occupational illness. It may be possible to use pharmacological approaches to reduce symptoms, or to use nicotine patches to reduce transdermal absorption.

Epidemiological research on the occupational health of disenfranchised populations is often difficult, but it is extremely important. Members of these populations are often the most difficult members of a society to locate and to follow up, yet they frequently bear a disproportionate share of health problems. This study demonstrated the usefulness of survey regression techniques for correlated data, in combination with popular epidemiological methods, for this important work. By providing the first estimates of this occupational illness, this study establishes green tobacco sickness as a significant occupational illness. It also begins the process of identifying the actual risk factors that need to be tackled to reduce the burden of this occupational illness.

Funding: this research was supported by grant R01 OH/ ES03648 from the National Institute of Occupational Safety and Health, and the National Institute of Environmental Health Sciences.

Conflicts of interest: none

POLICY IMPLICATIONS

- Tobacco production continues in developed and developing countries. Those most at risk for occupational illnesses related to tobacco production, including green tobacco sickness, are low income workers who cultivate and harvest the crop. National governments must implement and support occupational safety programmes for these and all farmworkers.

- Health care providers need more accurate information about occupational health risks of the communities they serve. Many of these occupational health risks, such as green tobacco sickness, transcend national boundaries. International health organisations, such as the World Health Organisation, should implement and support a system of communicating timely occupational health information to those caring for underserved populations.

- Research should be conducted to establish the long term health effects of transdermally absorbed nicotine. This will require the cooperation of occupational epidemiologists and agricultural scientists. Agricultural interests must be partners in the design and implementation of this research or they will probably impose barriers to its successful completion.

THOMAS A ARCURY

SARA A QUANDT
1 Gehlbach SH, Williams WA, Freeman JI. Protective clothing as a means of reducing nicotine absorption in tobacco haras a means of reducing nicotine absorption in

2 Gehlbach SH, Williams WA, Perry LD, et al. Green-tobacco sickness. An illness of tobacco harvesters. $\mathcal{F} A M A 1974 ; 229$ : 1880-3.

3 CDC. Green tobacco sickness in tobacco harvesters. MMWR 1993;42:237-9.

4 Ives TJ. Use of dimenhydrinate in the treatment of green tobacco sickness. Drug Intell Clin Pharm 1983;17:548-9.

5 Edmonson WD. Green tobacco sickness (bradycardia in a young farmer). I Tenn Med Assoc 1996;89:85-6.

6 Hipke ME. Green tobacco sickness. South Med f 1993;86: 989-92.

7 Ghosh SK, Parikh JR, Gokani VN, et al. Studies on occupational health problems during agricultural operation of Indian tobacco workers. F Occup Med 1979;21:45-7.

8 Ghosh SK, Parikh JR, Gokani VN, et al. Studies on occupational health problems in tobacco workers. F Soc Occup Med 1980;29:113-17.

9 Ghosh SK, Sakala C, Gokani VN, et al. Occupational health problems among workers handling Virginia tobacco. Int Arch Environ Health 1986;58:47-52.

10 Ghosh SK, Gokani VN, Parikh JR, et al. Protection against "green symptoms" from tobacco in Indian harvesters: A preliminary intervention study. Arch Environ Health 1987; 42:121-3.

11 Ballard T, Ehlers J, Freund E, et al. Green tobacco sickness: occupational nicotine poisoning in tobacco workers. Arch Environ Health 1995;50:384-9.

12 McKnight RH, Levine EJ, Rodgers GC Jr. Detection of green tobacco sickness by a regional poison center. Vet Hum Toxicol 1994;36:505-10.

13 Weizenecker R, Deal WB. Tobacco cropper's sickness. f Fla Med Assoc 1970;57:13-14.

14 Gehlbach SH, Williams WA, Perry LD, et al. Nicotine absorption by workers harvesting green tobacco. Lancet 1975;i:478-80.

15 Quandt SA, Arcury TA, Preisser J, et al. Migrant farmworkers and green tobacco sickness: new issues for an ers and green tobacco sickness: new issues for
understudied disease. Am find Med 2000;37:307-15.

16 McKnight RH, Dawson SK, Westneat SC, et al. Delay among the general public in telephoning a poison center. Vet Hum Toxicol 1996;38:92-5.

17 Misumi J, Koyama W, Miura H. Two cases of green tobacco sickness in the tobacco harvesters and the absorption of nicotine through the skin in the rat. Fpn f Ind Health 1983; 25:3-9.

18 Benowitz NL, Lake T, Keller KH, et al. Prolonged absorption with development of tolerance to toxic effects after cutaneous exposure to nicotine. Clin Pharmacol Ther 1987;42:119-20.

19 Benowitz NL, Jacob P 3rd, Olsson P, et al. Intravenous nicotine retards transdermal absorption of nicotine: Evidence of blood flow-limited percutaneous absorption. Clin Pharmacol Ther 1992;52:223-30.

20 Benowitz NL, Zevin S, Jacob P 3rd. Sources of variability in nicotine and cotinine levels with use of nicotine nasal spray, transdermal nicotine, and cigarette smoking. Br $\mathcal{F}$ Clin Pharmacol 1997;43:259-67.

21 Guy RH, Hadgraft J. Mathematical models of percutaneous absorption. In: Bronaugh RL, Maibach HI, eds. Percutaneous absorption: mechanisms-methodology-drug delivery. New York: Marcel Dekker, 1981:13-26.

22 Hardman JG, Gilman AG, Limbird LE. Goodman and Gilman's the pharmacological basis of therapeutics. 9th ed. New York: McGraw-Hill, 1996

23 Arcury TA, Quandt SA, Austin CK, et al. Implementation of US-EPA's Worker Protection Standard training for agricultural laborers: an evaluation using North Carolina data. Public Health Rep 1999;114:459-68.

24 Mehta K, Gabbard SM, Barrat V, et al. A demographic and employment profile of United States Farmworkers. Based on data from the National Agricultural Workers Survey. Washington, DC: US Department of Labor, Office of the Assistant Secretary for Policy, prepared for the Commission on Immigration Reform, 2000

25 SAS Institute I. SAS/STAT software: changes and enhancements through Release 6.12. Cary, NC: SAS Institute, 2000

26 Binder DA. On the variances of asymptotically normal estimators from complex surveys. International Statistical Review 1983;51:279-92.

27 Liang K-Y, Zeger SL. Longitudinal data analysis using generalized linear models. Biometrika 1986;73:13-22.

28 Shah BV, Barnwell BG, Bieler GS. SUDAAN user's manual, Release 7.5. Research Triangle Park, NC: Research Triangle Institute, 1997.

29 Lavange LM, Keyes LL, Koch GG, et al. Application of sample survey methods for modeling ratios to incidence densities. Stat Med 1994;13:343-55.

30 McKnight RH, Koetke CA, Donnelly C. Familial clusters of green tobacco sickness. F Agromedicine 1996;3:51-9. 